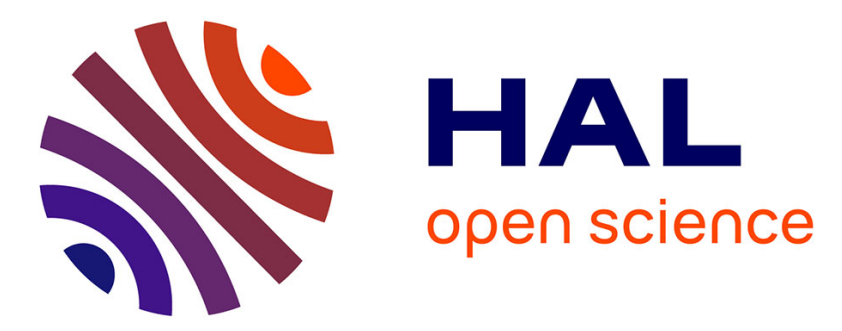

\title{
Atomic-plane-thick reconstruction across the interface during heteroepitaxial bonding of InP-clad quantum wells on Silicon
}

\author{
Anne Talneau, Christophe Roblin, A. Itawi, Olivia Mauguin, Ludovic Largeau, \\ G. Beaudoin, Isabelle Sagnes, Gilles Patriarche, Chengxin Pang, Henri Benisty
}

\section{To cite this version:}

Anne Talneau, Christophe Roblin, A. Itawi, Olivia Mauguin, Ludovic Largeau, et al.. Atomic-planethick reconstruction across the interface during heteroepitaxial bonding of InP-clad quantum wells on Silicon. Applied Physics Letters, 2013, 102, pp.212101. 10.1063/1.4807890 . hal-00857660

\section{HAL Id: hal-00857660 \\ https://hal-iogs.archives-ouvertes.fr/hal-00857660}

Submitted on 16 Nov 2015

HAL is a multi-disciplinary open access archive for the deposit and dissemination of scientific research documents, whether they are published or not. The documents may come from teaching and research institutions in France or abroad, or from public or private research centers.
L'archive ouverte pluridisciplinaire HAL, est destinée au dépôt et à la diffusion de documents scientifiques de niveau recherche, publiés ou non, émanant des établissements d'enseignement et de recherche français ou étrangers, des laboratoires publics ou privés. 


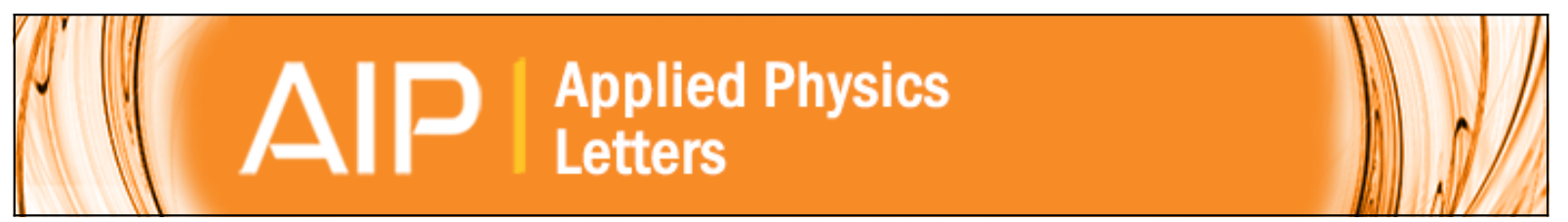

Atomic-plane-thick reconstruction across the interface during heteroepitaxial bonding of InP-clad quantum wells on silicon

A. Talneau, C. Roblin, A. Itawi, O. Mauguin, L. Largeau, G. Beaudouin, I. Sagnes, G. Patriarche, C. Pang, and H. Benisty

Citation: Applied Physics Letters 102, 212101 (2013); doi: 10.1063/1.4807890

View online: http://dx.doi.org/10.1063/1.4807890

View Table of Contents: http://scitation.aip.org/content/aip/journal/apl/102/21?ver=pdfcov

Published by the AIP Publishing

\section{Articles you may be interested in}

Improved electrical properties of wafer-bonded $\mathrm{p}-\mathrm{GaAs} / \mathrm{n}-\mathrm{InP}$ interfaces with sulfide passivation

J. Appl. Phys. 103, 094503 (2008); 10.1063/1.2912717

Low temperature In P/Si wafer bonding using boride treated surface

Appl. Phys. Lett. 90, 161102 (2007); 10.1063/1.2724922

Low-temperature In P/Ga As wafer bonding using sulfide-treated surface

Appl. Phys. Lett. 88, 061104 (2006); 10.1063/1.2172024

InGaAs quantum wells on wafer-bonded In $\mathrm{P} / \mathrm{Ga}$ As substrates

J. Appl. Phys. 98, 093526 (2005); 10.1063/1.2130889

Interface of directly bonded GaAs and InP

J. Appl. Phys. 89, 1017 (2001); 10.1063/1.1331068

\section{AIP $\left.\right|_{\text {APL Photonics }}$}

APL Photonics is pleased to announce Benjamin Eggleton as its Editor-in-Chief

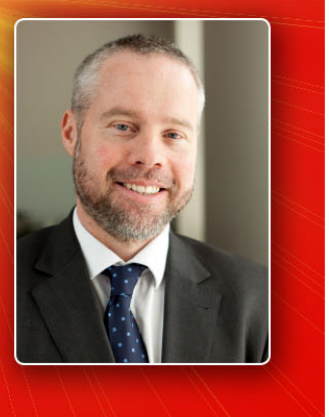




\title{
Atomic-plane-thick reconstruction across the interface during heteroepitaxial bonding of InP-clad quantum wells on silicon
}

\author{
A. Talneau, ${ }^{1, a)}$ C. Roblin, ${ }^{1}$ A. Itawi, ${ }^{1}$ O. Mauguin, ${ }^{1}$ L. Largeau, ${ }^{1}$ G. Beaudouin, ${ }^{1}$ I. Sagnes, ${ }^{1}$ \\ G. Patriarche, ${ }^{1}$ C. Pang,${ }^{2}$ and H. Benisty ${ }^{2}$ \\ ${ }^{1}$ Laboratoire de Photonique et de Nanostructures, Route de Nozay, F-91460 Marcoussis, France \\ ${ }^{2}$ Laboratoire Charles Fabry, CNRS, Univ Paris Sud, 2 Ave Fresnel, Palaiseau, France
}

(Received 14 February 2013; accepted 8 May 2013; published online 28 May 2013)

\begin{abstract}
An oxide-free heteroepitaxial bonding of InP-clad GaInAs quantum wells on Si showing an atomicplane-thick reconstruction across the InP-Si interface and no degradation of the quantum wells luminescence is demonstrated. Several InP surface preparation procedures have been investigated to ensure an oxide-free bonding. Such a bonding procedure without oxide or metal mediation allows embedding very-high-index-contrast nanostructuration within optic and optoelectronic integrated devices, thus enabling tailored designs enhancing dedicated optical functions. Heteroepitaxial bonding is also similarly obtained on nanopatterned Si surface. (C) 2013 AIP Publishing LLC.
\end{abstract}

[http://dx.doi.org/10.1063/1.4807890]

The future of integrated optics shall crucially hinge on silicon, due to the very efficient performances of silicon photonics and the well established Si processing technology. But light emission and optical isolation are optical functions that cannot be performed efficiently on Si-based materials. Bonding III-V InP-based materials on Si or Silicon-onInsulator (SOI) is thus still mandatory for operation of integrated devices emitting in the $1.55 \mu \mathrm{m}$ wavelength domain. III-V semiconductor light sources integrated on Si by direct bonding have already been demonstrated under oxide mediated bonding ${ }^{1,2}$ or including an intermediate amorphous bonding layer. ${ }^{3-6}$

We propose that when optoelectronic devices are concerned, oxide-free bonding should be preferred since it is reported to demonstrate advantageous electrical interface quality compared to oxide mediated bonding. ${ }^{7}$ Efficient electrical properties have been demonstrated for InGaAs bulk layers oxide-free bonded on $\mathrm{Si}$ in the case of silicon-based avalanche photodiodes ${ }^{8,9}$ some times ago, or much more recently in the case of $\mathrm{InAs} / \mathrm{GaAs}$ quantum dot lasers on $\mathrm{Si}^{10,11}$

When investigating advanced optical designs, it is also preferable to avoid any connex or continuous low-opticalindex amorphous layer of poor thermal conductivity in the core of the guiding layers formed by the two bonded materials. Oxide-free bonding will fully preserve any included structuration thus producing the highest index contrast enabling complex and efficient optical functions. As an example, an embedded photonic crystal was found to strongly enhance extraction efficiency in GaN-based light-emitting diodes. ${ }^{12}$

Heteroepitaxial bonding has been demonstrated in order to associate GaAs/AlGaAs Bragg mirrors on InP-based cavities for $1.55 \mu \mathrm{m}$ Vertical Cavity Surface Emitting Lasers (VCSEL). ${ }^{13,14}$ In this bonding, the grain boundary features a

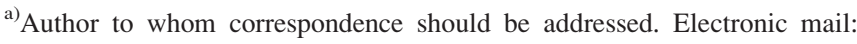
anne.talneau@lpn.cnrs.fr.
}

reduced lattice mismatch $(\sim 4 \%)$ and III-V to III-V material interface.

Considering the above advantages, we investigated heteroepitaxial bonding in order to associate at die size $\left(\sim 1 \mathrm{~cm}^{2}\right)$ either InP layers or InP-clad GaInAs quantum wells (QWs) on $\mathrm{Si}$. In this bonding, the grain boundary now features a large lattice mismatch of $8.1 \%$ and III-V to IV material interface.

It is well known that processing InP surfaces is critical, when compared to GaAs due to the surface chemistry of phosphor species. We demonstrate here that operating under oxide-free surface preparation and oxide-free bonding conditions produces an InP-Si reconstructed interface free of oxidation and amorphization. No dislocation is threading in either material lattices, the dislocations that accommodate the $8.1 \%$ lattice mismatch are located in the grain boundary extending solely on a single atomic layer. ${ }^{15} \mathrm{X}$-ray characterization demonstrates the very good crystallinity of the bonded material, as also corroborated by nanoindentation measurement. ${ }^{16} \mathrm{We}$ also report here the preservation of the photoluminescence (PL) wavelength and intensity of the bonded wells grown intentionally close to the surface $(71 \mathrm{~nm})$.

As far as device processing is concerned, both bonded materials behave just like a new single reconstructed material that can be processed for cleaving, thinning, annealing, and chemical mechanical polishing (CMP), which are very often mandatory technological steps for device processing.

Such bonding has been obtained both on a flat Si surface, for which we report a detailed characterization, as well as, in a device perspective, on a nanopatterned SOI surface, which demands specific characterization to be reported later.

In order to obtain an oxide-free heteroepitaxial interface, oxide-free surfaces preparation as well as oxide-free bonding conditions are both mandatory. Surface preparation of silicon in order to obtain an oxide-free $\mathrm{Si}$ surface is well documented. ${ }^{17,18}$ First a solvent ultrasonic cleaning is performed in order to eliminate any dust induced by cleaving, then the so-called RCA cleaning eliminates any possible contamination and finally HF (4\%) dipping during $30 \mathrm{~s}$, with a short $5 \mathrm{~s}$ 
rinsing in DI water, forms the last step. The low HF concentration is chosen to avert any surface roughness formation. ${ }^{17}$ The short rinsing duration is preferred since a longer stay in water could re-form $-\mathrm{OH}$ links, thus embedding $\mathrm{O}$ atoms at the interface. ${ }^{18}$ After this procedure, the $\mathrm{Si}$ surface is perfectly hydrophobic which is a signature of a deoxidized $\mathrm{Si}$ surface; such a deoxidized surface can be preserved during at least $30 \mathrm{~min}$ without any noticeable re-oxidation, thus the Si surface is prepared first.

Several InP-surface preparations have been duly investigated. Whatever the oxidation/deoxidation processes, we could not obtain an hydrophobic InP surface which is proposed to be the signature of an oxide-free surface as reported in Ref. 17. So we performed X-ray Photo-electron Spectroscopy (XPS) of the prepared InP surfaces in order to assess their oxide-free characteristic. The best oxide-free preparation process includes a first deoxidation performed with concentrated HF, then a reoxidation by pure inductively coupled plasma (ICP) $\mathrm{O}_{2}$ process without bias, and finally a deoxidation performed with concentrated HF. Such a process produces a hydrophilic surface, in agreement with Ref. 19, which is oxide-free under XPS. The kinetics of InP surface re-oxidation was also investigated, demonstrating that a concentrated HF solution and a short waiting time should be preferred (to be published). Oxide-free InP surface is then immediately brought into contact with the $\mathrm{Si}$ surface and bonding is initiated under vacuum. When operating without additional atoms to mediate $\mathrm{Si}$ to $\mathrm{InP}$ covalent bonds reconstruction, bonding has to be performed at a temperature large enough to allow In and $\mathrm{P}$ atoms to move at the atomic scale so as to re-arrange their structural lattice for locally matching the Si lattice. Detailed characterizations presented in this paper have been obtained for annealing at $550{ }^{\circ} \mathrm{C}$, during $90 \mathrm{~min}$ under vacuum. We have also demonstrated oxide-free bonding at temperatures down to $440{ }^{\circ} \mathrm{C}$, just slightly above the congruent sublimation temperature of InP. A low $0.2 \mathrm{MPa}$ pressure is applied in order to keep the two wafers in physical contact. The pressure uniformity has been carefully checked to ensure a homogeneous contact all along the two atomic surfaces.

A membrane including QWs has been bonded on an unpatterned as well as a nanopatterned Si substrate. The wafer is grown by Metal-Organic Vapor Phase Epitaxy (MOVPE); the membrane is composed of four GaInAs wells with GaInAsP barriers, with a 71-nm-thick InP bonding layer keeping intentionally the wells still rather close to the bonded interface. All layers are lattice-matched on the InP substrate. The membrane also includes a 300-nm-thick InGaAs sacrificial layer onto the InP top buffer layer in order to chemically remove the InP substrate by selective etching. For both experiments, this substrate removal step uses an $\mathrm{HCl}$ solution, while the GaInAs stop etch layer itself is removed by selective wet etching. Operating at die size, we consider small pieces for bonding investigation. The initial InP die is $\sim 5 \mathrm{~mm} \times 5 \mathrm{~mm}$ bonded on a $1 \mathrm{~cm}^{2} \mathrm{Si}$ wafer piece. The die is bonded on its entire surface; after chemical substrate removal the bonded membrane is reduced to $\sim 4 \mathrm{~mm} \times 4 \mathrm{~mm}$ since the $\mathrm{HCl}$ solution also laterally etches the InP bonding layer.

We performed two tests that are preliminary technologyoriented bonding assessments: (1) we thinned the Si substrate by CMP or the InP substrate by mechanical polishing without any membrane delamination and (2) we cleaved the bonded membrane on $\mathrm{Si}$ substrate, and a SEM inspection of the cleaved interface revealed no void. These tests indicate that the membrane bonded on the substrate behaves in most respects just like a new single reconstructed material.

In-depth structural characterization as well as PL measurements was performed to investigate the interface and the quantum wells quality for this reconstructed material. For the purpose of clear interpretation of spectra, X-ray characterization is performed on a single $400 \mathrm{~nm}$ thick InP membrane bonded under the same procedure. For Scanning Transmission Electron Microscope (STEM) and PL characterization, the QW membrane described above bonded at $550{ }^{\circ} \mathrm{C}$ on the unpatterned Si substrate has been used. The PL characterization is performed for both the $550^{\circ} \mathrm{C}$ heteroepitaxial oxide-free bonding and a thick BCB (BenzoCycloButene) $300^{\circ} \mathrm{C}$ bonding process, which could be considered as a reference since the original wafer itself includes the GaInAs etch stop layer which prevents direct PL measurement.

High resolution X-ray diffraction and grazing incidence $\mathrm{X}$-ray diffraction measurements have been realized using a versatile Rigaku Smartlab X-ray diffractometer equipped with a rotating anode. Fig. 1(a) presents the intensity of the (004) diffraction peaks as a function of the angular position of the detector, for two azimuths separated by $180^{\circ}$. On the right-hand side (at $2 \theta=69.131^{\circ}$ ), the peaks originate from the lattice of the Si substrate. Both peaks at $2 \theta=63.2875^{\circ}$ are due to the (004) planes of the InP membrane. Both measurements performed at two azimuths separated by $180^{\circ}$ evidence a tilt value $\sim 0.05^{\circ}$ in the $\langle 110\rangle$ direction between the bonded InP and Si substrates. This good result is to be attributed to the hydrophobic preparation of the surfaces prior to bonding. Fig. 1(b) presents the diffraction peaks produced by the (220) planes normal to the (001) surface for both Si substrate and InP membrane. The $2 \theta=47.35^{\circ}$ for the $\mathrm{Si}(220)$ planes being the reference, we obtain for the InP (220) a value of $2 \theta=43.58^{\circ}$ which is close to the unbounded (220) InP one. From this difference and after calibration, the upper limit for the twist angle is determined to be $0.1^{\circ}$. Moreover, the very small angular width of the bonded-InP peaks is a strong evidence of the very good crystallinity of the bonded material.

This good crystallinity is also assessed by previously published mechanical characterization of the grain boundary through nanoindentation measurements performed with a Berkovich diamond pyramid on the same InP bonded membrane, that has shown pop-in load comparable to the one obtained under the same experimental conditions for a bulk specimen. ${ }^{10}$

An in depth STEM analysis of the bonded interface has been performed on a JEOL 2200FS equipment, including an $\mathrm{X}$-ray analysis. In Fig. 2(b), the four wells are visible, as well as a white In inclusion at the bonded interface. In Fig. 2(a), both crystalline lattices of $\mathrm{Si}$ (bottom right) and InP (top left) are visible, without any amorphous layer at the interface. A sharp $8 \%$ lattice variation corresponding to the lattice difference has been measured by geometrical phase analysis (GPA) cartography (Fig. 2(c)). Scarce oxygen inclusions could be found; the most often found, though, were In 
(a)
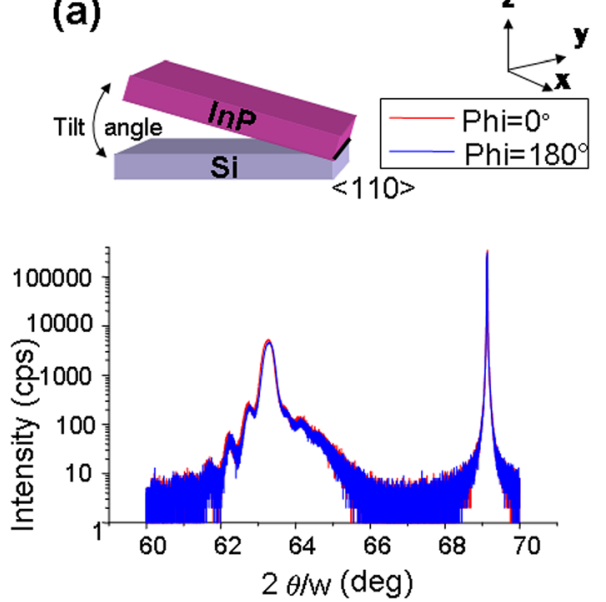

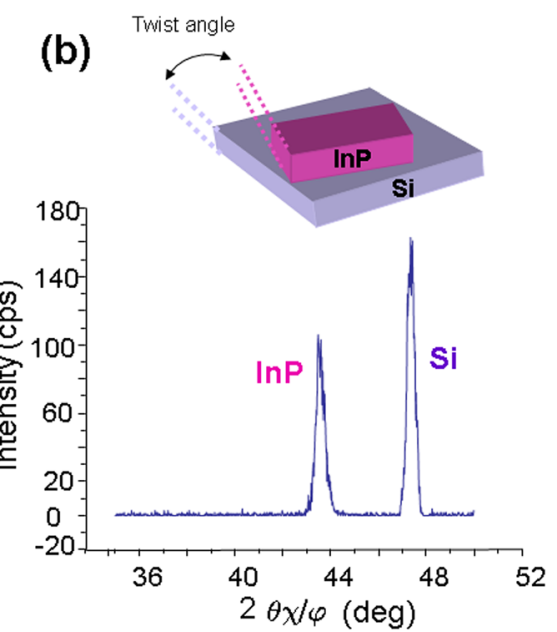

FIG. 1. (a) High resolution X-ray diffraction of (004) planes along two azimuths, and (b) grazing incidence X-ray diffraction of (220) planes perpendicular to the surface. inclusions, as shown in Fig. 2(b). The dislocations required to accommodate the large lattice mismatch are systematically located in the grain boundary, which extends on a single atomic layer. Thus, the crystalline structures of the $\mathrm{Si}$ and the InP crystals are completely unaffected.

Optical characterization of the bonded wells is performed by photoluminescence measurement under optical pumping at $980 \mathrm{~nm}$. This pumping energy has been chosen to lie within the barriers, in order to prevent the photogenerated carriers to escape in the InP interface layer. In this wafer dedicated to bonding experiment, the four quantum wells have been grown close to the bonding interface (InP bonding layer $71 \mathrm{~nm}$ thick) in order to evidence, if any, the impact of the heteroepitaxial bonding process on the quantum well luminescence. Fig. 3 shows the PL spectra at $300 \mathrm{~K}$ for the same bonded wafer under the same cw pumping and detection conditions, under two bonding processes: a $300{ }^{\circ} \mathrm{C} 1-\mu$ m-thick BCB bonding process (solid line) and the $550{ }^{\circ} \mathrm{C}$ heteroepitaxial bonding process (dotted line). The measurement accuracy of the PL maximum wavelength is in the range $\pm 1 \mathrm{~nm}$. $\mathrm{BCB}$ bonding using a thick $\mathrm{BCB}$ layer could be considered as a reference since the PL of the bonded wafer itself could not be measured due to the presence of the InGaAs etch stop layer required for substrate
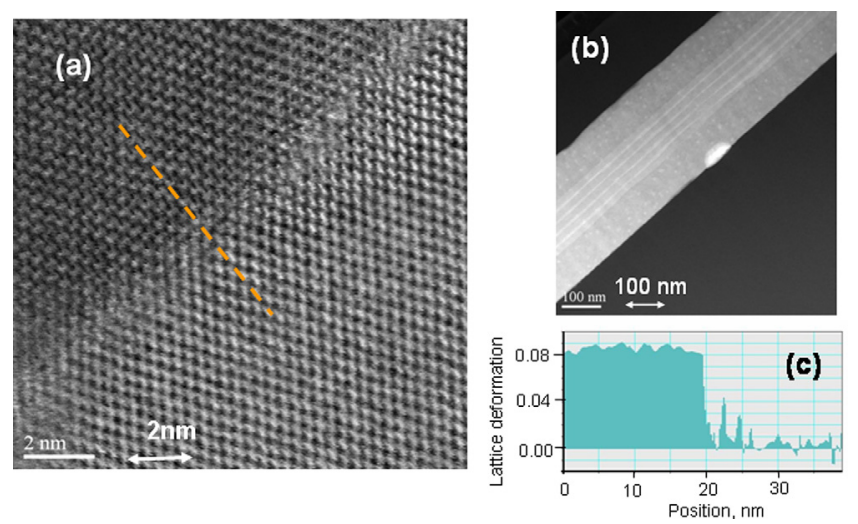

FIG. 2. (a) Bright field STEM micrograph of the bonded interface showing both Si lattice (right) and InP lattice (left). (b) Bright field STEM micrograph of the bonded stack and interface with an In inclusion. (c) GPA cartography performed through the interface (dashed yellow line as an eye guideline) showing the abrupt interface transition between the two crystal lattices. removal. Such a common BCB bonding process has no detrimental impact on the QW. Fig. 3 shows that both luminescence energy maxima and PL intensity are nearly identical for the bonded wafer under the two bonding conditions. For the heteroepitaxial bonding process, the differential thermal expansion coefficient between InP and $\mathrm{Si}$ during the thermal cycle from room temperature to $550^{\circ} \mathrm{C}$ has been estimated to induce a tensile strain of $0.1 \%$, thus resulting in a $+4 \mathrm{~nm}$ shift of the emitted wavelength using first principle calculation. Such a thermal behavior is also present in the BCB bonded wafer, with a lower impact due to the lower thermal excursion. The difference in the PL maximum shift due to thermal expansion between the two bonding processes will then lie within the accuracy of the PL measurement. We can conclude that the preserved PL wavelength and intensity indicate that heteroepitaxial bonding produces no degradation of the quantum wells, even when they are located at only $71 \mathrm{~nm}$ off the bonded interface.

For hybrid III-V-onto-Si integrated devices, a nanopatterned $\mathrm{Si}$ waveguide design was proposed to provide tailored guided modes for dedicated optical functions. ${ }^{20}$ A $2 \mathrm{D}$ array

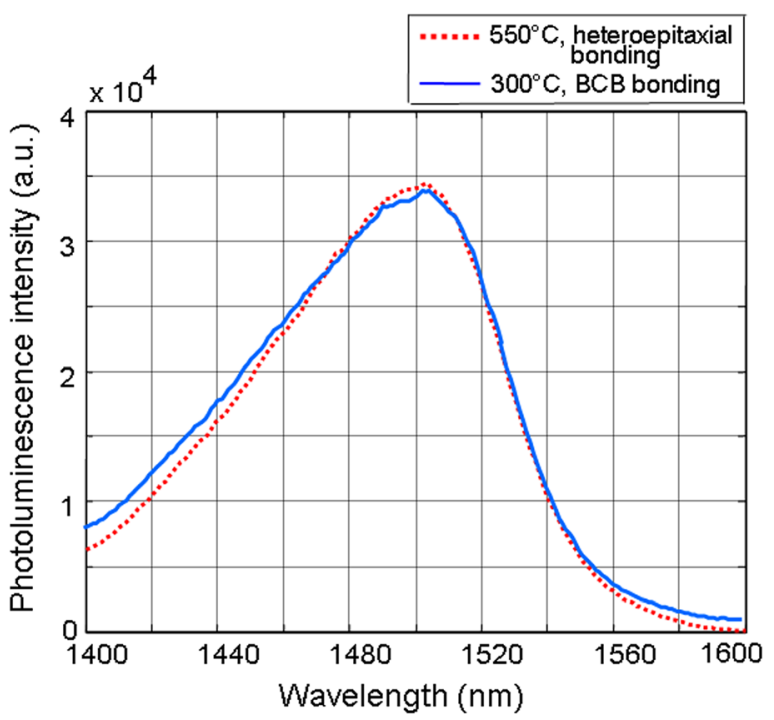

FIG. 3. Photoluminescence spectra at $300 \mathrm{~K}$ under optical pumping at $980 \mathrm{~nm}$ : (solid line) $300^{\circ} \mathrm{C}$ BCB bonding of the same QW stack, which could be considered as a "reference;" (dotted-line) $550^{\circ} \mathrm{C}$ heteroepitaxial bonding. 


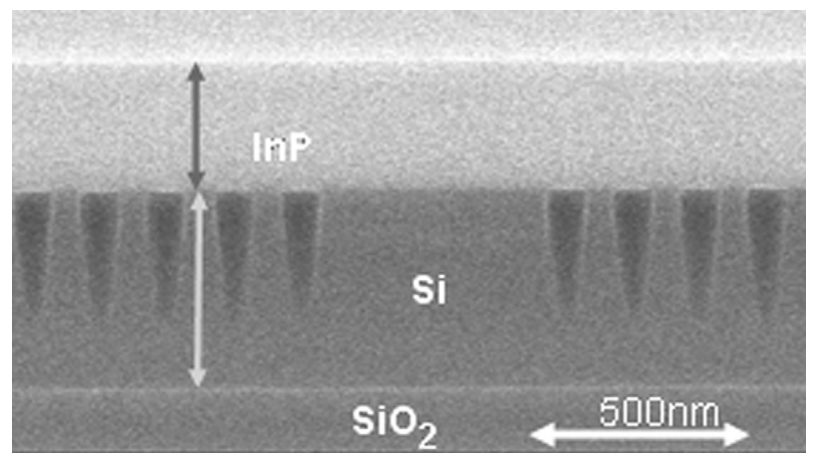

FIG. 4. SEM image of a cleaved facet from a bonded InP membrane (top layer) on a SOI structure with nanopatterned lateral cladding.

of holes ensures the lateral confinement; it operates as an effective medium when designed at a period below its photonic gap. E-beam patterning and ICP dry-etching are used to produce nanopatterned waveguides in the Si guiding layer of a SOI substrate. Oxide-free bonding is performed after the same oxide-free surfaces preparation. A 400-nm-thick InP bonded membrane has shown positive results through both CMP thinning and cleaving test. Fig. 4 shows a SEM view of a cleaved facet where both crystallographic cleavage planes of InP (top layer) and Si (bottom layer) are properly aligned. Detailed structural and mechanical characterization will be reported elsewhere.

In conclusion, we have demonstrated oxide-free heteroepitaxial bonding of InP-clad GaInAs quantum wells on unpatterned as well as nanopatterned $\mathrm{Si}$ surface. Bonding is performed at $550{ }^{\circ} \mathrm{C}$ for oxide-free surfaces and under oxidefree conditions, and has also been demonstrated at temperatures down to $440{ }^{\circ} \mathrm{C}$. Oxide-free InP surface preparation has been deeply investigated. In the case of unpatterned Si surfaces, in-depth characterizations of bonded wafers that include quantum wells demonstrate an atomic-plane-thick reconstruction across the InP-Si interface. GaInAs bonded wells are also shown to preserve perfectly their luminescence energy and intensity.

Oxide-free bonding on patterned $\mathrm{Si}$ surface opens the route to nanostructured integrated devices fabricated on SOI wafers. This oxide-free bonding technique is promising for integrated devices including an embedded nanostructuration with a very-high-contrast for dedicated optical functions, which improve the photonic integrated circuit functionality.

${ }^{1}$ A. W. Fang, H. Park, Y. Kuo, R. Jones, O. Cohen, D. Liang, O. Raday, M. N. Sysak, M. J. Paniccia, and J. E. Bowers, Mater. Today 10, 28 (2007).

${ }^{2}$ S. Srinivasan, A. W. Fang, D. Liang, J. Peters, B. Kaye, and J. E. Bowers, Opt. Express 19, 9255 (2011).

${ }^{3}$ G. Roelkens, J. Van Campenhout, J. Brouckaert, D. Van Thourhout, R. Baets, P. R. Romeo, P. Regreny, A. Kazmierczak, C. Seassal, X. Letartre, G. Hollinger, J. M. Fedeli, L. Di Cioccio, and C. Lagahe-Blanchard, Mater. Today 10, 36 (2007).

${ }^{4}$ S. Stanković, R. Jones, M. N. Sysak, J. M. Heck, G. Roelkens, and D. Van Thourhout, IEEE Photon. Technol. Lett. 23, 1781 (2011).

${ }^{5}$ J. Van Campenhout, P. R. Romeo, P. Regreny, C. Seassal, D. Van Thourhout, S. Verstuyft, L. Di Cioccio, J. Fedeli, C. Lagahe, and R. Baets, Opt. Express 15, 6744 (2007).

${ }^{6}$ M. Lamponi, S. Keyvaninia, C. Jany, F. Poingt, F. Lelarge, G. de Valicourt, G. Roelkens, D. Van Thourhout, S. Messaoudene, J.-M. Fedeli, and G. H. Duan, IEEE Photon. Technol. Lett. 24, 76 (2012).

${ }^{7}$ D. Pasquariello, M. Camacho, K. Hjort, L. Dozsa, and B. Szentpali, Mater. Sci. Eng., B 80, 134 (2001).

${ }^{8}$ A. R. Hawkins, T. E. Reynolds, D. R. England, D. I. Babic, M. J. Mondry, K. Streubel, and J. E. Bowers, Appl. Phys. Lett. 68, 3692 (1996).

${ }^{9}$ W. Wu, A. R. Hawkins, and J. E. Bowers, J. Lightwave Technol. 15, 1608 (1997).

${ }^{10}$ K. Tanabe, K. Watanabe, and Y. Arakawa, Sci. Rep. 2, 349 (2012).

${ }^{11}$ K. Tanabe, K. Watanabe, and Y. Arakawa, Opt. Express 20, B315 (2012).

${ }^{12}$ E. Matioli, E. Rangel, M. Iza, B. Fleury, N. Pfaff, J. Speck, E. Hu, and C. Weisbuch, Appl. Phys. Lett. 96, 031108 (2010).

${ }^{13}$ A. Karim, P. Abraham, D. Lofgreen, Y.-J. Chiu, J. Piprek, and J. Bowers, Appl. Phys. Lett. 78, 2632 (2001).

${ }^{14}$ G. Patriarche, F. Jeannès, J.-L. Oudar, and F. Glas, J. Appl. Phys. 82, 4892 (1997).

${ }^{15}$ A. Talneau, C. Roblin, A. Itawi, O. Mauguin, L. Largeau, G. Beaudouin, I. Sagnes, and G. Patriarche, in IPRM'2012, Santa Barbara, 2012, Paper No. Tu-2E.2.

${ }^{16}$ E. Le Bourhis, A. Talneau, I. Sagnes, G. Patriarche, L. Largeau, and D. Troadec, Heteroepitaxial bonding of Si for hybrid photonic devices (Mater. Res. Soc. Symp. Proc. 2013), Vol. 1510.

${ }^{17}$ Q.-Y. Tong and U. Gösele, Semiconductor Wafer Bonding (Wiley, New York, 1998).

${ }^{18}$ G. W. Trucks, K. Raghavachari, G. S. Higashi, and Y. J. Chabal, Phys. Rev. Lett. 65, 504 (1990).

${ }^{19}$ Y. Sun, Z. Liu, F. Machuca, P. Pianetta, and W. E. Spicer, See www.slac.stanford.edu/cgi./slac-pub-11018.pdf for SLAC-PUB-11018 (2005).

${ }^{20} \mathrm{C}$. Pang and H. Benisty, Photonics Nanostruct. Fundam. Appl. 11, 145 (2013). 